Original article

\title{
AGILE PROJECT MANAGEMENT AS AN ANSWER TO CHANGING ENVIRONMENT
}

\author{
Suzana Balaban ${ }^{1}$, Jasmina Đurašković ${ }^{2}$
}

\begin{abstract}
${ }^{1}$ Alfa BK University, Faculty of Finance, Banking and Auditing, Serbia

${ }^{2}$ Educons University, Faculty for Project and Innovation Management, Serbia
\end{abstract}

Received: 26 November 2020 Revised: 17 December 2020 Accepted: 31 March 2021

\begin{abstract}
The high level of volatility, uncertainty, complexity and ambiguity in business environments lead to the fact that traditional management has been in serious trouble. The required flexibility should provide the agile project management causing a silent revolution of the way projects are organized and executed. Although initially rooted in the software development industry, we can say that agile methodologies are spreading across a broad range of industries. The benefits of applying an agile approach are widely recognized, but there are still various challenges and problems that the organization faces with when adopting an agile practice.
\end{abstract}

Keywords: Agile methodology, project management.

\section{INTRODUCTION}

There is an increasing demand for the innovative and complex projects. Although the best practices in traditional project management have been widely applied since 1960 (Crawford, 2006; Shenhar, \& Dvir, 2007), there are some barriers in their implementation in the innovative and complex projects (Maylor, 2001). Bearing in mind the high level of uncertainty and complexity in a business environment, Bogsnes (2016) conclude that traditional management has been in a serious trouble. Sahota et al. (2014) shows that a traditional management is not in accordance with the circumstances to which the companies are exposed in a changing environment. Knaster and Leffingwell (2017) and Mahadevan et al. (2015) confirm this claim. Dawson and Dawson, 1998; Perminova et al., 2008 criticize the use of traditional management especially in the companies engaged in developing the new products or technologies. The traditional management incorporates detailed planning that is not in accordance with the innovation projects that include a high level of the uncertainty and complexity. (Davies, \& Brady, 2016; Paluch, et al, 2020). A more flexible approach adaptable to the contingencies of the project environment is required (Biazzo, 2009).

The agile project management has been widely used in recent years as a way to counter the dangers of traditional methods. (Serrador, \& Pinto, 2015). The agile project management is rooted in the software development industry as an iterative approach with a focus on the small batches, transparency, relationship with the customer and feedback (Qumer, \& HendersonSellers, 2008; Sheffield, \& Lemétayer, 2013). Over the past 30 years the agile innovations have boosted the motivation and productivity of IT companies worldwide (Rigbi, et al., 2016).

According to Dybå and Dingsøyr (2008) the agile project management methods caused a silent revolution of the way projects are organized and executed. For the profit organizations the most important question is how limited resources have to be invested in order to maximize revenue in changing environment (Berk, \& DeMarzo, 2017; Rieg, 2015). The required flexibility should provide an agile development (Rumpe, 2017). Applied

Corresponding author. Email: suzana.balaban@alfa.edu.rs

ISSN 2560-4961 (online)

Copyright (C) 2021, The Authors. Published by IPMA Serbia.

This is an open access article under the CC BY-NC 4.0 license (https://creativecommons.org/licenses/bync/4.0/) 
the agile approaches lead to an increased project efficiency as well as the stakeholder and project members' satisfaction (Overhage, $\&$ Schlauderer, 2011). However, there are a lot of problems related to application of the agile approach (Serrador, \& Pinto, 2015). Hence, the agile budgeting should also be described as a challenging task (Hogue, 2014).

The research questions are: Does changing environment require an agile approach? Does agile approach work outside software industry? Whether the potential benefits outweigh the problems arising from the application of agile methodologies in practice? In accordance with the research question, this paper is structured as follows. In the next section of this paper we introduce the literature review, while the third section deal with agile in practice. In the fourth section there are presented the benefits and challenges that companies experienced when they apply an agile approach, while the fifth section concludes. The limit of this paper is the fact that we only summarize the results of the past studies.

\section{LITERATURE REVIEW}

The traditional project management approaches often fail to achieve the required objectives of innovative projects (Bianchi, et al., 2020). The challenging environment has been leading to a new understanding of project management. Agile practices become increasingly popular offering firms a higher flexibility (Kaufmann, et al., 2020). The fundamental assumptions of the traditional development implies that systems are predictable and built through the extensive plans. Contrary to that, the agile development include the adaptive software using the principles of continuous improvement based on feedback. The other main differences between the traditional and agile development are shown in Table 1.

Table 1: The main differences between traditional and agile development

\begin{tabular}{lll}
\hline & Traditional development & Agile development \\
\hline $\begin{array}{l}\text { Kanagement style } \\
\text { Communication }\end{array}$ & Command and control & Leadership and collaboration \\
Development model & Explicit & Tacit \\
Desired organizational & Lormal & $\begin{array}{l}\text { The evolutionary-delivery } \\
\text { model }\end{array}$ \\
structure & $\begin{array}{l}\text { Mechanistic, aimed at large } \\
\text { organization }\end{array}$ & $\begin{array}{l}\text { Organic, aimed at small and } \\
\text { medium organizations. }\end{array}$ \\
Quality control & $\begin{array}{l}\text { Heavy planning, strict control, } \\
\text { heavy testing }\end{array}$ & $\begin{array}{l}\text { Continuous control of } \\
\text { requirements, design and } \\
\text { solutions. }\end{array}$ \\
\hline
\end{tabular}

Source: Dybå and Dingsøyr (2008)

The most of earlier studies have considered the issue: how should we align agile with the traditional management practices? Sahota et al. (2014) considered a different question: how should the traditional management practices be transformed in order to take full advantages of agile? Beyond budgeting was created as an alternative management model following the few EU and US organizations' practices in the late $1990 \mathrm{~s}$ in order to transform any organization to agile one. Similarly, Saynisch (2010) propose Project Management Second Order based on new insights in the modern natural and social sciences as a new paradigm for the next decades that should be implemented in different companies.
Jahr (2014) proposes a modified multi-mode resource constrained project scheduling model for software projects that can be used to generate schedules as benchmarks for agile development iterations. This approach can be a useful especially for software projects with the predefined deadlines and budgets. Stettina and Hörz (2015) based on 30 interviews conducted in 14 large European organizations, try to answer the question on how to enable agility outside of individual projects. Conforto and Amaral (2008) shows the benefits of using simple, iterative, visual, and agile techniques to plan and control innovative product projects combined with traditional project management best practices in two technology-based companies in Brazil. Conforto et al. (2014) examine the use of agile project management 
practices in 19 medium- and large-sized companies showing the opportunities to adapt the agile project management practices for different companies. Using a data sample of 1002 projects across multiple industries and countries, Serrador and Pinto (2015) find the positive impact of the agile methods on efficiency and overall stakeholder satisfaction against the organizational goals. Malik et al. (2021) show that the agile practices lead to the innovative behaviour of agile teams.

\section{AGILE IN PRACTICE}

We can say that the agile methodologies are spreading across a broad range of industries. For example, John Deere uses them to develop the new machines, Saab to produce new fighter jets. (Rigbi, et al., 2016). In order to facilitate the valuation of certain classes of projects NASA has been used real options analysis. (Hawes, \& Duffey, 2008).

In order to transform their research and development unit in accordance with the agile software development Sirkiä and Laanti (2013): eliminate the cost control at the project level, create a better visibility of the results, focus on competence limitations, separate allocation of important investments, emphasize transparency, define the roles and responsibilities. As a result, a finance and control process becomes lean itself focusing only on total cost allowing content management to be agile. According to Fewell (2012) an agile budgeting implies a trust and can be implemented in the several ways:

- Teams rather than project as the unit of work - a better estimation of spending in the particular area.

- Re-establish cost centers - provide a higher level of granularity.

- New ways of monitoring progress sprint review as a way to evidence the team progress.
- Enable the agile teams to be flexible without additional re-budgeting and re-allocating people.

- Estimate a fixed, reliable iteration burn rate - a better decision based on expected iterations and cost.

Although the agile methodologies are less useful in routine operations, the most companies operate in highly dynamic environment that requires innovation in functional processes and the agile approach (Rigbi, et al., 2016).

According to Jardine (2019) there are four strategies for establishing project budgeting: (1) All key elements are included in the project - in order to estimate a realistic budget, agile team define all stakeholders' expectations. (2) Refining the budget - calculate how much the project will really cost by including uncertainty. (3) Collaborative approach to manage feature prioritization - enables the stakeholders to monitor the progress of the project. (4) Budget as a creator of refined product - the product becomes both refined and targeted.

After surveying 216 agile practitioners, Tam et al. (2020) show that team capability and customer involvement are the main factors contributing to the success of on-going agile software development projects.

The 14th Annual State of Agile Report includes individuals from a range of industries in the global software development community. Between August and December 20191.121 full survey responses were collected, analyzed and prepared into a summary report that shows that the most common applied agile methodology are: Scrum (58\%), ScrumBan (10\%), Hybrid combined with multiple methodologies (9\%), Scrum in combination with XP hybrid (8\%), Kanban (7\%) and Iterative development (4\%) that is shown in Figure 1. 


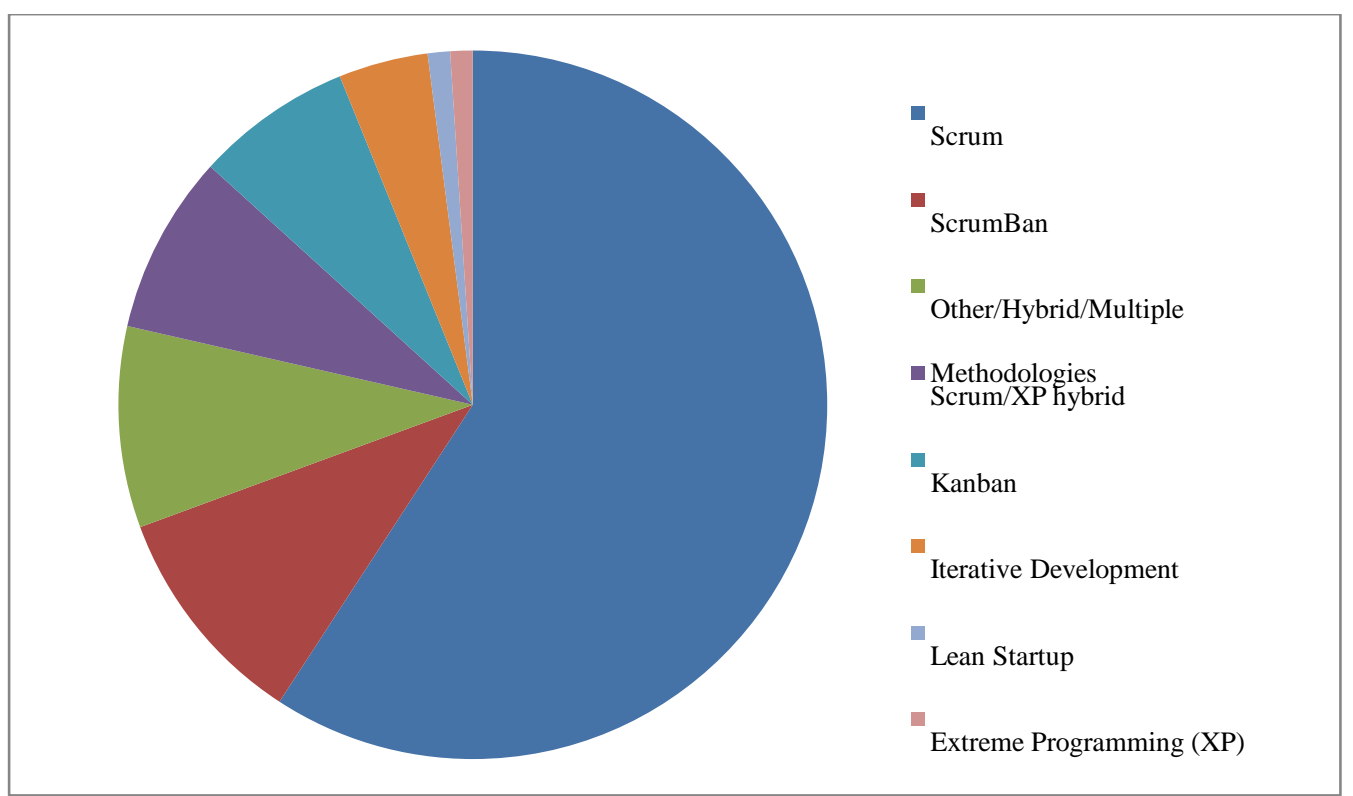

Figure 1: The applied methodologies of agile approach

Source: The 14th Annual State of Agile Report

\section{THE KEY BENEFITS AND \\ CHALLENGES FROM APPLYING AN AGILE APPROACH}

Before an implementation of an agile approach, organizations rooted in traditional development should applied pre-designed project (Mahadevan, et al., 2015).

The 14th Annual State of Agile Report shows that the individuals from a range of industries in the global software development community as the most benefits of the agile practice mentioned: ability to manage changing priorities $(70 \%)$, project visibility $(65 \%)$, business/IT alignment (65\%), increased delivery speed $(60 \%)$, better team morale $(59 \%)$, increased team productivity (58\%), project risk reduction $(51 \%)$ and better project predictability $(50 \%)$. In Figure 2 are shown other benefits from applying an agile approach.

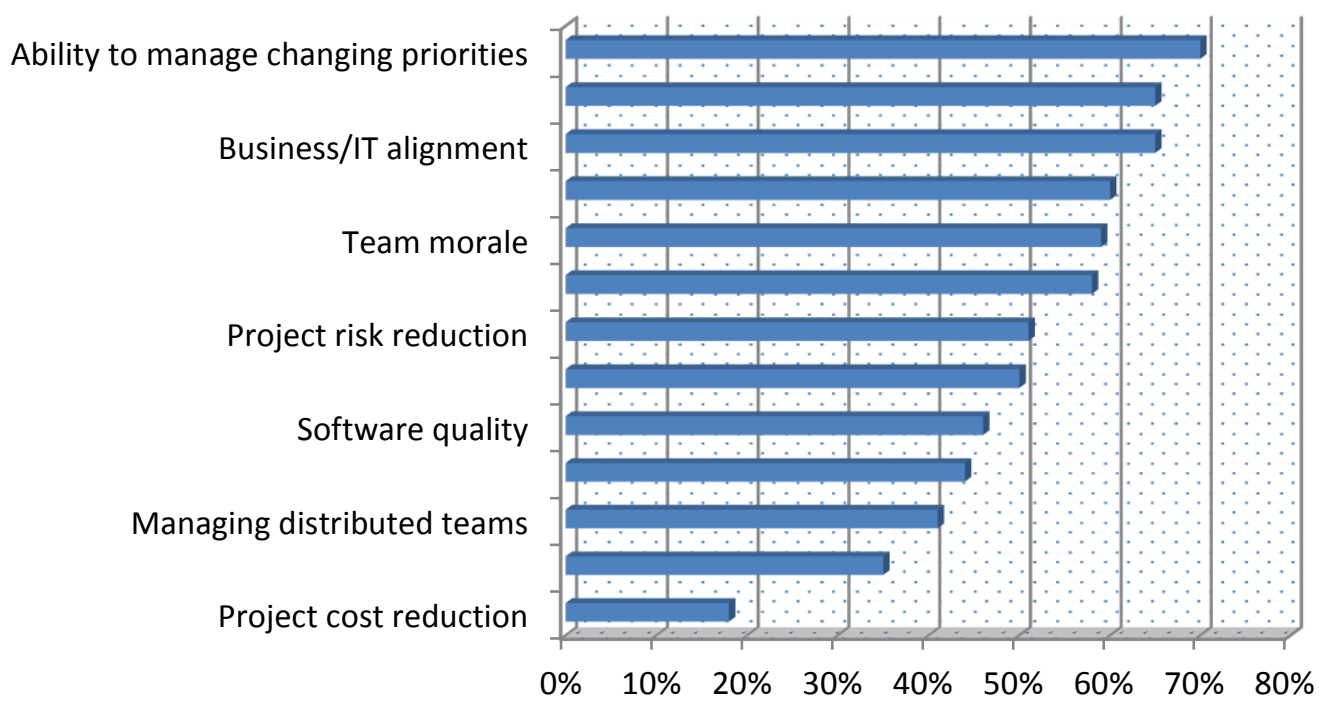

Figure 2: The key benefits from using an agile approach

Source: The 14th Annual State of Agile Report 
Fewell (2012) as the main benefits of the agile projects states: (1) stable team roster and (2) time-boxed iterations. Sirkiä and Laanti (2013) find that the agile finance and control process: focus on total cost allowing content management to be agile, can more precisely predict some indicators, needs less resources, while R\&D unit become freer in accordance with execution velocity and latest priorities. Mahadevan et al. (2015) shows that an implementation of the agile methodologies shifted some of controller authority from the information system function to the business function.

An implementation of the agile methodologies in the case of Curaspan company leads to following benefits: (1) more precisely insight into the revenues, (2) the revenue predictions determine the investment decisions, (3) faster decision-making, (4) instead of projects the teams are funded, (5) teams are viewed as the interchangeable resources, (6) giving priority to velocity, (7) avoiding redundant requirements or codes, (8) increase transparency. Using a data sample of 1002 projects across multiple industries and countries, Serrador and Pinto (2015) test the effect of the agile practice in organizations on two dimensions of the project success: efficiency and overall stakeholder satisfaction against organizational goals. Their findings suggest that agile methods have a positive impact on both dimensions.

Agile teams value customer cooperation, which should be a base of the agile budgeting in every organization that implements an agile approach. The organizations that want to implement an agile approach to budgeting consider development work as an investment, not as a usual transaction. As well as the other financial investment, development is speculative and there are no guarantees for success.

Transition from the traditional to agile approach is not easy due to the fact that two approaches are very different. The agile approach is less-structured with more unspecified outcomes. Consequently, it requires a daily interaction. An implementation of the agile approach includes a modification in development approach that relies on teams. (Mahadevan, et al., 2015).

The general organization resistance to change (48\%), not enough leadership participation $(46 \%)$ and inconsistent processes and practices across teams $(45 \%)$ are the most common challenges experienced in the different organization in the case when they adopt the agile approach. The other challenges and problems the organization faced with are presented in Figure 3.

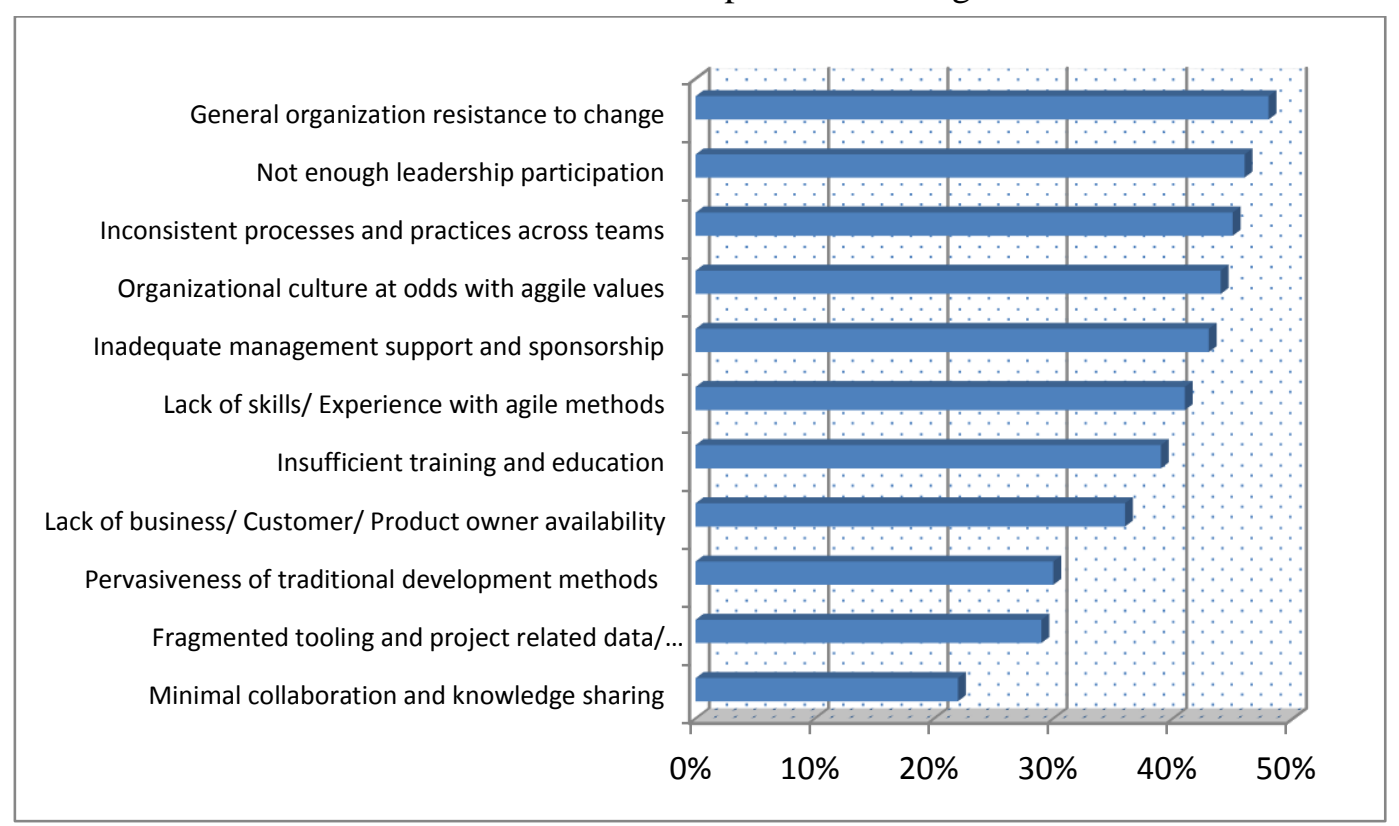

Figure 3: Challenges experienced when adopt the agile practice Source: The 14th Annual State of Agile Report 


\section{CONSLUSION}

The traditional project management approaches often fail to achieve the required objectives of innovative projects. A project complexity definition is necessary in order to cope with the project management challenges. The agile practices become popular for projects offering firms a higher flexibility to adapt to the changing environments.

Although the agile project management is rooted in the software development industry, we may say that agile approach also works outside software industry. However, the organizations thinking of adopting agile practices should answer the essential question "What do they want to achieve?" It is possible that what the company wants isn't actually a problem agile addresses. Implementation of the agile approach is speculative and there are no guarantees for success.

Although the benefits of applying the agile approach are widely known and recognized by both managers and employees (such as an ability to manage changing priorities, better project visibility, good business/IT alignment, higher team morale, increased team productivity etc.), there are still various challenges and problems that the organization faces with when adopting the agile practice. The main challenges experienced when adopting the agile practice remain general organization resistance to change, not enough leadership participation and inconsistent processes and practice across teams.

The limit of this paper is the fact that we only summarize the results of the research conducted by other authors. For further research we recommend an observation of the implementation of the agile practice in Serbia's companies with reference on the realized benefits, applied methodologies and experienced challenges.

\section{REFERENCES}

Berk, J., \& DeMarzo, P. (2017). Corporate Finance - Global Edition. Pearson, London.

Bianchi, M., Marzi, G., \& Guerini, M. (2020). Agile, Stage-Gate and their combination: Exploring how they relate to performance in software development. Journal of Business Research, 110, pp. 538-553. https://doi.org/10.1016/j.jbusres.2018.05 .003

Biazzo, S. (2009). Flexibility, structuration, and simultaneity in new product development. Journal of Product Innovation Management, 26(3), pp. 336353. https://doi.org/10.1111/j.1540$\underline{5885.2009 .00662 . \mathrm{x}}$

Bogsnes, B. (2016). Implementing Beyond Budgeting: Unlocking the Performance Potential, $2^{\text {nd }}$ edition, John Wiley \& Sons

Conforto, E. C., \& Amaral, D. C. (2008). Evaluating an Agile Method for Planning and Controling Innovative Projects. Projects Management Journal, 41(2), pp. 73-80.

https://doi.org/10.1002/pmj.20089

Conforto, C. E., Salum, F., Amaral, D. C., De Silva, S. K., \& de Almeida, L. F. M. (2014). Can Agile Project Management Be Adopted by Industry Other than Software Development? Project Management Journal, 45(3), pp. 21-34. https://doi.org/10.1002/pmj.21410

Crawford, L. (2006). Developing organizational project management capability: Theory and practice. Project Management Journal, 37(3), 74-86. https://doi.org/10.1177/87569728060370 $\underline{0308}$

Davies, A., \& Brady, T. (2016). Explicating the dynamics of project capabilities. International Journal of Project Management, 34, pp. 314-327. https://doi.org/10.1016/j.ijproman.2015. $\underline{04.006}$

Dawson, R., \& Dawson, C. (1998). Practical proposals for managing uncertainty and risk in project planning. International Journal of Project Management, 16(5), pp. 299-310.

https://doi.org/10.1016/S02637863(97)00059-8

Dybå, T., \& Dingsøyr, T. (2008). Empirical studies of agile software development: A systematic review. Information and Software Technology, 50(9-10), pp. 833859.

Fewell, J. (2012). Big agile. PM Network, 26(5), p. 66 
Hawes, W. M., \& Duffey, M. R. (2008). Formulation of Financial Valuation Methodologies for NASA's Human Spaceflight Project. Project Management Journal, 39(1), pp. 85-94. https://doi.org/10.1002/pmj.20032

Hogue, I. (2014). Managing the Impossible with an Agile Budget. Available at: https://www.leadingagile.com/2014/04/a gile-budgeting retrieved July 12, 2020.

Jardine, O. (2019). How to Calculate Agile Project Budgets (and Stick to Them). Project Management. https://blog.capterra.com/how-tocalculate-agile-project-budgets-andstick-to-them/

Jahr, M. (2014). A Hybrid Approach to Quantitative Software Project Scheduling Within Agile Framework. Project Management Journal, 45(3), pp. 35-45. https://doi.org/10.1002/pmj.21411

Kaufmann, C., Kock, A., \& Gemünden, H. G. (2020). Emerging strategy recognition in agile portfolios. International Journal of Project Management, 38, pp. 429-440. https://doi.org/10.1016/j.ijproman.2020. 01.002

Knaster, R., \& Leffingwell, D. (2017). SAFe ${ }^{\circledR}$ 4.0 Distilled: Applying the Scaled Agile Framework for Lean Software and Systems Engineering, Addison-Wesley, Boston, MA.

Mahadevan, L., Ketinger, W. J., \& Meservy, T. O. (2015). Running on hybrid: Control changes when introducing an agile methodology in a traditional 'waterfall' system development environment. Communications of the Association for Information System, 36, pp. 77-103. https://doi.org/10.17705/1CAIS.03605

Malik, M., Sarwar, S., \& Orr, S. (2021). Agile practices and performance: examining the role of psychological empowerment. International Journal of Project Management, 39, pp. 10-20. https://doi.org/10.1016/j.ijproman.2020. 09.002

Maylor, H. (2001). Beyond the Gantt chart. European Management Journal, 19(1), 92-100.

Overhage, S., \& Schlauderer, S. (2011). Investigating the long-term acceptance of agile methodologies: An empirical study of developer perceptions in Scrum projects, in Proceedings of the Annual Hawaii International Conference on System Sciences, pp. 5452-5461.

Paluch, S., Antons, D., \& Brettel, M. (2020). Stage-gate and agile development in the digital age: Promises, perils, and boundary conditions. Journal of Business Research, 110C, pp. 495-501. https://doi.org/10.1016/j.jbusres.2019.01 .063

Perminova, O., Gustafsson, M., \& Wikström, K. (2008). Defining uncertainty in project: a new perspective. International Journal of Project Management, 26(1), pp. 73-79. https://doi.org/10.1016/j.ijproman.2007. 08.005

Qumer, A., \& Henderson-Sellers, B. (2008). An evaluation of the degree of agility in six agile methods and its applicability for method engineering. Information and Software Technology, 50(4), pp. 280-295. https://doi.org/10.1016/j.infsof.2007.02. $\underline{002}$

Rigbi, D. K., Sutherland, J., \& Takeuchi, H. (2016). Embracing Agile. Harvard Business Review

Rieg, R. (2015). Planung und Budgetierung. $2^{\text {nd }}$ edition, Springer, Berlin. https://doi.org/10.1007/978-3-83494629-4

Rumpe, B. (2017). Agile Modeling with UML. Springer,

Berlin.

https://doi.org/10.1007/978-3-31958862-9

Sahota, M., Bogsnes, B., Nyfjord, J., Hesselberg, J., \& Drugovic, A. (2014). Beyond Budgeting: A Proven Governance System Compatible with Agile Culture, Agile Alliance.

Saynisch, M. (2010). Mastering Complexity and Changes in Project, Economy, and Society via Project Management Second Order (PM-2). Project Management Journal, 41(5), pp. 4-20. https://doi.org/10.1002/pmj.20167

Serrador, P., \& Pinto, J. K. (2015). Does Agile work? - A quantitative analysis of agile project success. International Journal of Project Management, 33(5), pp. 10401051.

https://doi.org/10.1016/j.ijproman.2015. 
$\underline{01.006}$

Sirkiä, R., \& Laanti, M. (2013). Lean and agile financial planning. Available at https://www.nitor.com/application/files/ 8314/6737/4669/Whitepaper-24-Dec2013-Lean-and-Agile-FinancialPlanning.pdf

Shenhar, A. J., \& Dvir, D. (2007). Project management research - The challenge and opportunity. Project Management Journal, 38(2), pp. 93-99. https://doi.org/10.1177/87569728070380 $\underline{0210}$

Sheffield, J., \& Lemétayer, J. (2013). Factors associated with the software development agility of succesful projects. International Journal of Project Management, 31(3), pp. 459-472. https://doi.org/10.1016/j.ijproman.2012. $\underline{09.011}$

Stettina, C. J., \& Hörz, J. (2015). Agile portfolio management: an empirical perspective on the practice in use. International Journal of Project Management, 33, pp. 140-152. https://doi.org/10.1016/j.ijproman.2014. $\underline{03.008}$

Tam, C., da Costa Moura, E. J., Oliveira, T., \& Varajao, J. (2020). The factors influencing the success of ongoing agile software development projects. International Journal of Project Management, 38 (3), pp. 165-176.

The $14^{\text {th }}$ annual State of Agile Report. (2020). VersionOne Inc,

https://stateofagile.com/\#ufh-i615706098-14th-annual-state-of-agilereport/7027494 